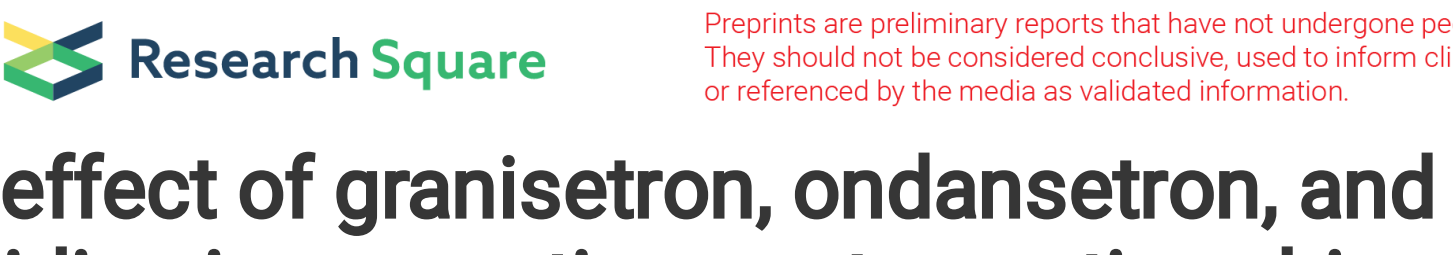 \\ The effect of granisetron, ondansetron, and
pethidine in preventing postoperative shivering: controlled clinical trial
}

\section{Masood Entezariasl}

Ardabil university of medical sciences

Hamed Zandian

Ardebil University of Medical Sciences

Khatereh Isazadehfar ( $\square$ isazadehfar@yahoo.com )

Ardabil University of Medical Sciences https://orcid.org/0000-0003-0584-4213

Research article

Keywords: Shivering, Postoperative, Granisetron, Pethidine, Ondansetron

Posted Date: December 23rd, 2019

DOI: https://doi.org/10.21203/rs.2.19384/v1

License: (c) (i) This work is licensed under a Creative Commons Attribution 4.0 International License.

Read Full License 


\section{Abstract}

Background: recently, use of HT35 receptor antagonists to prevent postoperative shivering has attracted a great deal of attention. Therefore, the present study was conducted with the aim of investigating the effectiveness of granisetron as an HT35 antagonist when compared with ondansetron and pethidine in preventing postoperative shivering.

Methods: in this triple blind random clinical trial study, 90 patients $18-50$ years of age with ASA Class I and II undergoing general anesthesia were randomly assigned into one of the three drug groups: 0 (4-mg ondansetron), G (40 $\mu \mathrm{g} / \mathrm{kg}$ of granisetron), and P (25 mg pethidine), immediately before induction of anesthesia. After anesthesia induction, at the end of the surgery, after the entrance and after leaving the recovery state, central temperature, peripheral temperature, systolic blood pressure, diastolic blood pressure, heart rate, and shivering were measured and recorded. P-value less than 0.05 was considered statistically significant.

Results: in the pethidine, ondansetron, and granisetron groups, 4 (13.3\%), $3(10 \%)$, and $10(33.3 \%)$ of patients experienced shivering during recovery, where the difference between the ondansetron and granisetron groups was significant ( $p$-value $=0.02$ ). The variations in the mean arterial pressure during the investigation stages were not significant only in the ondansetron group $(p>0.05)$. At the beginning of recovery, the reduction of peripheral temperature was significantly lower in the ondansetron group $(p<0.05)$, while reduction of the central temperature was higher in the granisetron group $(p<0.05)$. By the end of the recovery, the changes in the peripheral temperature across the three groups were consistent with the changes at the beginning of recovery, but no significant difference was observed variations of the central temperature across the three groups.

Conclusion: Granisetron was not found to be much effective in preventing postoperative shivering. Ondansetron and pethidine were equally effective in preventing postoperative shivering. Ondansetron also causes less hemodynamic changes compared to other drugs, while granisetron is more effective in terms of preventing nausea and vomiting

\section{Background}

The body central temperature is one of the most important and stable parameters in preserving the physiology of the human body. Any disorder in this parameter including hypothermia during surgical operation results in problems such as postoperative shivering, coagulation disorders, impaired nitrogen balance of the body, and changes of pharmacological effects on the human body (1).

In studies, mild hypothermia has resulted in a three-fold increase in the risk of developing shivering following cardiac operation. Thus, even preventing mild hypothermia should be considered important (2).

Postoperative shivering is one of the most common complications after surgery which is observed in $6.3-65 \%$ of patients, and include involuntary movements of one or several groups of muscles (3). 
The postoperative shivering event is very common and causes various complications such as increased oxygen uptake, increased carbon dioxide production, elevated heart rate and blood pressure, and thus aggravation of ischemic heart disease (4). Other complications include increased intracranial pressure, increased intraocular pressure, increased pain at the site of surgery, and discomfort and malaise in the patient (5). General anesthesia facilitates redistribution of temperature from central tissues to peripheral tissues. In response to anesthesia, the responses of the central temperature regulation such as the vascular contraction threshold are inhibited where most anesthetic agents cause peripheral vasodilation $(4,6)$.

Shivering can be a result of hypothermia during surgical operation and re-regulation of the body heat center or due to secondary fever and chills in response to activation of inflammatory response and release of cytokines (7).

To reduce shivering, there are pharmacological and nonpharmacological methods. The nonpharmacological method involves use of moisturizers, preventing hypothermia with the help of warming blankets, and inhaling warm and humid oxygen. The pharmacological method, on the other hand, most exerts its effect through reducing the shivering temperature threshold (3).

However, which pharmacological method is more suitable for patients following surgery is still controversial.

To prevent postoperative shivering, various pharmacological methods have been used, where pethidine has been known as one of the most effective drugs (8). Most probably, pethidine exists its effect on temperature regulation center or through opioid central receptors.

Granisetron and ondansetron have also been used in some studies to prevent postoperative shivering and have had positive effects (9-12). These medications exert their anti-vomiting effects through antagonistic effects of serotonin receptors at the end of the vagus nerve and its central receptors in the vomiting center. In this way, by inhibiting vomiting reflex, they prevent nausea and vomiting and can be used to prevent postoperative nausea and vomiting. Serotonin (5-hydroxy tryptamine) is a biological amine which is found in the brain and nerve fiber and has a neuro- transmitting role. Some studies believe that the serotonergic system is involved in controlling postoperative shivering (12).

Eventually, since no study was found on comparing the effect of ondansetron, granisetron, and pethidine in preventing postoperative surgery, the present study was conducted with the aim of comparing ondansetron and granisetron when compared with pethidine as a well-known drug in preventing and treating postoperative surgery.

\section{Method}

\section{Study design and setting}


The present study is a triple blind randomized clinical trial study that was conducted in Ardabil University of Medical Sciences (ARUMS) as one of northwestern medical universities of Iran

\section{Sample}

Since the probability of reduction of incidence of shivering using ondansetron in previous studies was around $40 \%$ compared to the control group with $\alpha=0.05$ and $\beta=0.2$, the sample size required in each group was obtained as 29 to allow detection of a difference between groups with a power of $80 \%$.

Finally, 30 patients (18-50-year-old), who had referred to Imam Khomeini Hospital affiliated with ARUMS for general surgery, after obtaining a written informed consent regarding the medications to be used preoperatively from each patient were considered for each group.

\section{Exclusion Criteria:}

Very obese patients (a weight above $100 \mathrm{~kg}$ ), patients with a fever above $38^{\circ} \mathrm{C}$, those with a history of endocrine diseases and Parkinson's disease, the patients who needed blood transfusion or peripheral vasodilators or vasoconstrictors, and the subjects whose surgical operation lasted for more than 90 minutes were excluded from the research.

\section{Insert Figure 1 here}

\section{Study process and variables}

The patients were blocked randomly and placed in one of the three groups of ondansetron, granisetron, and pethidine. For the first, second, and third groups, $4 \mathrm{mg}$ of ondansetron, 40 $\mu \mathrm{g} / \mathrm{kg}$ of granisetron, and $25 \mathrm{mg}$ of pethidine were intravenously injected respectively two minutes before the initiation of anesthesia. All of the three utilized drugs were prepared in identical 2-cc syringes where the anesthesiologist responsible for controlling and recording the clinical signs was not informed about the type of drug injected to the patients. 
Induction of anesthesia was initiated by injecting fentanyl $1 \mu \mathrm{g} / \mathrm{kg}$, propofol $2 \mathrm{mg} / \mathrm{kg}$, and atracurium $0.5 \mathrm{mg} / \mathrm{kg}$ in the same way for all of the three groups. After tracheal intubation, the anesthesia was sustained through infusion of propofol $100 \mu \mathrm{g} / \mathrm{kg} / \mathrm{m}$ along with an inhalation gas mixture containing 50\% oxygen and 50\% N2O. To preserve muscular relaxation during the operation, atracurium $0.5 \mathrm{mg} / \mathrm{kg}$ was injected and the patients were ventilated mechanically throughout the surgery.

For all of the patients when entering the operation room, the central temperature was measured and recorded through tympanic method, and the skin temperature was measured through the forehead skin. Further, systolic blood pressure, diastolic blood pressure, and heart rate of patients were also recorded and the mentioned points were measured and recorded again immediately after induction of anesthesia, during the surgery, and after entrance of the patient to the recovery room, and by the time patient left the recovery state.

The operation and recovery room temperature was also recorded by thermometer which was kept at $20-22^{\circ} \mathrm{C}$ during the entire time of surgery.

After entrance of patients to the recovery room and during the duration of residence in recovery, observation of postoperative shivering in the form of shivers of the face, trunk, or limbs which continued for at least 15 seconds were recorded by an anesthesiology resident who was not aware of the type of injected drug. The shiver score was $0-4$, and it will be graded as follows: 


\begin{tabular}{|l|c|}
\hline Clinical Symptoms & $\begin{array}{c}\text { Shivering } \\
\text { Grading }\end{array}$ \\
\hline Without shivering & 0 \\
\hline Occurrence of one or more of the following criteria: & 1 \\
\hline $\begin{array}{l}\text { Piloerection, peripheral vasoconstriction, peripheral cyanosis without other } \\
\text { specific cause, but without visible muscular contractions }\end{array}$ & 2 \\
\hline Contraction observed limited to a bunch of muscle contraction & 3 \\
\hline Contraction observed in more than one group of muscles & 4 \\
\hline The whole body clear muscular activity & \\
\hline
\end{tabular}

\section{Data Analysis}

Statistical analysis was conducted by SPSS 20. One-way ANOVA and Post hoc tests was used to comparing means of parametric data between three groups. Kruskal Wallis and chisquare tests to comparing means of nonparametric data between three groups were used. P-value less than 0.05 was considered statistically significant. This study adheres to CONSORT guidelines.

\section{Results}

The demographic characteristics including the age, gender, height, weight, and basic data of patients including duration of the operation and duration of anesthesia did not differ significantly across the three groups (Table 1).

Insert Table 1 here

In pethidine, ondansetron, and granisetron groups, 4 (13.3\%), 3 (10\%), and $10(33.3 \%)$ of patients respectively experienced shivering in the recovery room, where a significant difference existed between the groups ( $p$-value=0.04). In paired comparisons of groups, there was no significant difference between pethidine and ondansetron ( $p$-value $=0.05)$ as well as between pethidine and granisetron ( $p$-value $=0.063$ ) in terms of shivering. On the other hand, ondansetron and granisetron indicated a significant difference in this regard $(p-v a l u e=0.02, \mathrm{RR}=4.5, \mathrm{Cl}=1.09-18.5)$.

The number of patients with shivering grades of 4,3 , and 2 was higher in the granisetron, pethidine and ondansetron groups, respectively (Table 2). However, the observed difference was not statistically 
significant $(p=0.063)$.

Insert Table 2 here

In terms of hemodynamic variations when comparing the three groups, the changes in the mean arterial pressure during the investigation stages were not significant only in the ondansetron group. In this regard, it has been more effective than the two other drugs in developing hemodynamic stability (Table 3 ).

Insert Table 3 here

In terms of changes in the heart rate, significant variations were observed in the three groups in different stages of investigation, where the three drug groups were not significantly different in this regard (Table $3)$.

The verbal response time was statistically significant between the three groups ( $p$-value=0.045), where the longest time was related to granisetron with the mean of $12.01 \pm 1.26$, while the shortest time was found for ondansetron with the mean of $11.11 \pm 1.02 \mathrm{~min}$.

In investigating the complications across the three groups, 1 (3.3\%) of patients from both pethidine and ondansetron groups experienced nausea, while no such case was reported in the granisetron group $(p=0.6)$. Note that vomiting was not observed in any of the groups.

At the beginning of recovery, reduction of peripheral temperature was significantly lower in the ondansetron group compared to the two other groups $(p<0.05)$. Further, reduction of the central temperature was significantly greater in the granisetron group compared to the two other groups $(p<0.05)$.

At the end of recovery, changes in the peripheral temperature across the three groups were in line with those at the beginning of recovery, but no significant difference was observed changes of the central temperature between the three groups (Table 3 ).

\section{Discussion}

Preventing and treating postoperative shivering is an important part of patient care following surgical operations (9). The reason is that more serious complications may develop in the patient in response to sympathetic excitation, increased oxygen uptake, or increased carbon dioxide production (5).

In this study which, pethidine, ondansetron, and granisetron drugs were used, and their effects on preventing and controlling postoperative shivering were investigated in patients who have been surgically treated under general anesthesia. The extent of incidence of shivering in granisetron group was higher than pethidine and ondansetron. Thus, it can be inferred that ondansetron and pethidine have the same effectiveness when used before termination of surgery to decrease incidence of postoperative shivering. However, use of granisetron in reducing the extent of incidence of postoperative shivering has not been 
as effective as these two drugs. There was also a statistically significant difference between ondansetron and granisetron $(p=0.02)$.

Considering the effect of ondansetron on preventing incidence of postoperative shivering and comparing it with pethidine, various studies have been conducted, in most of which effectiveness of ondansetron has been emphasized. For example, in a study conducted by Entezari et al (9), for patients in the first, second, and third groups, $4 \mathrm{mg}$ of ondansetron, $0.4 \mathrm{mg} / \mathrm{kg}$ of pethidine, and $2 \mathrm{cc}$ normal saline solution were injected to patients respectively. Postoperative shivering was observed in $13.3 \%$ and $20 \%$ of the ondansetron and pethidine groups respectively, which showed reduction compared to the control group in which $50 \%$ of patients experienced shivering.

Further, based on the meta-analysis by Tie et al on the papers related to the effect of ondansetron postoperative shivering in 2014 when compared with placebo, ondansetron decreased the extent of postoperative shivering from $49.3 \%$ to $23.4 \%$, but it has had no special superiority over pethidine in mitigating shivering (15).

The effect of granisetron on reducing postoperative shivering has been examined in several studies. For example, in a study by Mohammadi et al on 100 patients undergoing C-section surgery with spinal anesthesia, the extent of incidence of postoperative shivering in the granisetron group was $8 \%$ versus $54 \%$ in the placebo group (5).

The study by Asif Iqbal in India suggested that the extent of postoperative shivering 15 min after the operation was lower in the granisetron and pethidine groups, compared to placebo (17 and $7 \%$ versus $60 \%)(12)$.

In the study by Sajedi et al, the extent of incidence of shivering in the granisetron group with a dose of 40 $\mu \mathrm{g} / \mathrm{kg}$ was 9 out of 33 and in pethidine group was 6 out of 33 (14).

Considering comparison of ondansetron and granisetron in preventing postoperative shivering, no similar study was found. Nevertheless, Reshad et al compared these two drugs on hemodynamic changes following spinal anesthesia. They concluded that ondansetron is more effective than granisetron in reducing hypotension (16), which is to a large extent in line with the results of the present study, in which hemodynamic changes have been lower in the ondansetron group than in the granisetron group.

The observed difference between these two drugs can be due to difference at the site of effect of ondansetron on mix receptors and more specific effect of granisetron on 5-hydroxy tryptamine receptors and its less affinity on other 5-hydroxy tryptamine, adrenergic, histaminergic, dopaminergic receptors and those of opiates (18).

Considering comparison of these drugs in preventing postoperative nausea and vomiting, Gupta et al (17) studied patients undergoing laparoscopy surgery. They concluded that the extent of nausea after operation was $30 \%$ in the ondansetron group, which was $10 \%$ in the granisetron group $(p<0.05)$. Kabade 
et al also concluded that prophylactic granisetron reduces the need of antiemetic's (19). This finding is also largely consistent with the results of our study.

The limitation of the present study was not assessing the effect of different doses of ondansetron and granisetron on reducing the extent of postoperative shivering. Also, use of placebo group can also be another limitation of the present study, which underrepresents the results of the present research.

\section{Conclusion}

Based on the findings, use of intravenous ondansetron $4 \mathrm{mg}$ when compared with granisetron $40 \mu \mathrm{g} / \mathrm{kg}$ has had a significant effect on preventing postoperative shivering, and has been as effective as pethidine. Further, hemodynamic changes by this drug have been lower than those of granisetron and pethidine, while granisetron has been more effective than these two drugs in terms of preventing nausea and vomiting.

\section{Declaration}

\section{Acknowledgement:}

The authors would like to offer their special thanks to the Research Deputy of Ardabil University of Medical Sciences for its support and providing funding for this research.

\section{Authors' contributions}

Study concept and design: ME \& Khl. Acquisition of data: ME \& Khl. Analysis and interpretation of data: $\mathrm{HZ} \&$ Khl. Drafting of the manuscript: HZ \& ME. Critical revision of the manuscript for important intellectual content: HZ. Statistical analysis: Khl \& HZ. Administrative, technical, and material support: ME. Study supervision: ME

\section{Funding}

This project was funded by Ardabil University of Medical Sciences (9115). ARUMS provided the financial support for the labor cost of data collection and the project-processing total costs. It also plays a supervisory role in design of the study, analysis and interpretation of data.

\section{Availability of data and materials}

Because of the secrecy policy restrictions on RCT studies, the datasets used in this study are not allowed to be deposited in publicly, but it is available for chief editor of the journal and is available from the corresponding author on reasonable request 


\section{Ethics approval and consent to participate}

This project is approved by ethical committee of ARUMS with reference number $904 / 1$ and got IRCT code with IRCT21204284093N4.

\section{Consent for publication}

Not applicable

\section{Competing interests}

One of the authors is Anesthesiology, but there are no conflicts of interest for declaration and all authors declare that they have no competing interest in relation with the subject of the manuscript.

\section{References}

1. Kurz A. Physiology of thermoregulation. Best Pract Res Clin Anaesthesiol. 2008 Dec; 22(4):627-44

2. Reynolds L, Beckmann J, Kurz A. Perioperative complications of hypothermia. Best Pract Res Clin Anaesthesiol. 2008 Dec; 22(4):645-57.

3. Hoseinkhan Z,Behzadi M. Morphine, Pethidine and Fentanyl in postoperative shivering control: a randomized clinical trial. Tehran University Medical Journal; Vol. 64, No.12, Mar 2007: 57-63

4. Zhou C, Zhu Y, Liu Z, Ruan L. 5-HT3 receptor antagonists for the prevention of postoperative shivering: a meta-analysis. J Int Med Res. 2016; 44:1174-1181.6.

5. Mohammadi SS, Jabbarzadeh S, Movafegh A. Efficacy of granisetron on prevention of shivering, nausea and vomiting during cesarean delivery under spinal anesthesia: A randomized double-blinded clinical trial. J Obstet Anaesth Crit Care 2015; 5:22-6.

6. ALFONSI P. Postanaesthetic shivering. Epidemiology, pathophysiology and approaches to prevention and management. MINERVA ANESTESIOL 2003; 69:438-41

7. Yared JP, Starr NJ, Hoffman-Hog L, Bashour CA, Insler SR, O'Connor M, Piedmonte M, Cosgrove DM. Dexamethasone Decreases the Incidence of Shivering After Cardiac Surgery: A Randomized, DoubleBlind, Placebo-Controlled Study. Anesth Analg. 1998; 87:795-9

8. Elvan EG, Oc B, Uzun S, Karabulut E, Coskun F, Aypar U. Dexmedetomidine and postoperative shivering in patients undergoing elective abdominal hysterectomy. Eur J Anaesthesiol. 2008; 25(5):357-64. doi: 10.1017/S0265021507003110. [PubMed: 18205960]

9. Entezari AM, Isazadefar KH, Mohammadian A, Khoshbaten M .Ondansetron and meperidine prevent postoperative shivering after general anesthesia. Middle East J Anaesthesiol 2011;21(1):67-70. 
10. Nesioonpour SH, Pipelzadeh MH, Mohtadi AR, Rezai S, Feghhi M, Malekshoar M. A Comparative Study of dexamethasone, granisetron and metoclopramide for prevention of nausea and vomiting after cataract surgery. Bina J Ophthalmol 2009; 14 (4): 413-419.

11. Safaeian R, SalehiN, Tamadon R M. Comparison between two drug combination effects on postoperative nausea and vomiting in abdominal operations (granisetron\& dexamethasone vs droperidol \& dexamethasone). Razi Journal of Medical Sciences 2005; 11(44):987-992.

12. Asif I, Ahsan A, A Rudra, Ravi GW, Saika TS, Tanmoy D, Debasis R. Prophylactic granisetron vs pethidine for the prevention of postoperative shivering: A Randomized Control Trial. Indian Journal of Anesthesia 2009; 53 (3):330-334.

13. Sagir O, Gulhas N, Toprak H, Yucel A, Begec Z, Ersoy O. Control of shivering during regional anaesthesia: prophylactic ketamine and granisetron. ActaAnaesthesiol Scand. 2007 Jan; 51(1):44-9.

14. Sajedi P, Yaraghi A, Moseli HA. Efficacy of granisetron in preventing postanesthetic shivering. Acta Anaesthesiol Taiwan 2008; 46:166-70.

15. Tie et al.: Efficacy and safety of ondansetron in preventing postanesthesia shivering: a meta-analysis of randomized controlled trials. BMC Anesthesiology 2014 14:12.

16. Rashad MM, Farmawy MS. Effects of intravenous ondansetron and granisetron on hemodynamic changes and motor and sensory blockade induced by spinal anesthesia in parturients undergoing cesarean section. Egyptian Journal of Anaesthesia (2013) 29, 369-374.

17. S Gupta, R Choudhary. A Comparative Clinical Study Of Prevention Of Post-Operative Nausea And Vomiting Using Granisetron And Ondansetron In Laparoscopic Surgeries. The Internet Journal of Anesthesiology. 2009; 26 (1)

18. Aapro M. Granisetron: an update on its clinical use in the management of nausea and vomiting. Oncologist 2004; 9: 673-86.

19. Kabade SD, Venkatesh Y, Karthik S, Kumar V. Comparative study of granisetron versus pethidine for the prevention of perioperative shivering under spinal Anesthesia. Karnataka Anaesth J 2016;2:14-8

\section{Tables}

\begin{tabular}{ccccl}
\hline \multicolumn{5}{c}{ Table 1: Demographic characteristics of groups } \\
\hline Pvalue & Granisetron & Ondansetron & Pethidine & \multicolumn{1}{c}{ Variable } \\
\hline 0.71 & $39.3 \pm 17.7$ & $42.6 \pm 17.6$ & $43.9 \pm 13$ & Age $(\mu \pm \delta)$ \\
0.48 & $10 / 20$ & $9 / 21$ & $6 / 24$ & Sex $(\mathrm{M} / \mathrm{F})$ \\
0.10 & $66.1 \pm 12.8$ & $72.6 \pm 14.7$ & $72.6 \pm 12.7$ & Weight $(\mu \pm \delta)$ \\
0.51 & $164.5 \pm 10.1$ & $162.6 \pm 10.1$ & $161.5 \pm 9.2$ & Height $(\mu \pm \delta)$ \\
0.88 & $74.1 \pm 27.7$ & $70.5 \pm 32.5$ & $71.8 \pm 25.5$ & Duration of Surgery (min) \\
0.87 & $98.8 \pm 32.5$ & $98.5 \pm 35.3$ & $94.9 \pm 26.9$ & Duration of Anesthesia (min) \\
\hline
\end{tabular}




\begin{tabular}{ccccc}
\hline \multicolumn{5}{c}{ Table2: Incidence and score of shivering in groups } \\
\hline Pvalue & Granisetron & Ondansetron & Pethidine & Variable \\
\hline $\mathbf{0 . 0 4}$ & $10(33.3)$ & $3(10)$ & $4(13.3)$ & Shivering in recovery $(\%)$ \\
$\mathbf{0 . 0 6 3}$ & $0 / 5 / 4 / 1$ & $0 / 0 / 1 / 2$ & $0 / 3 / 0 / 1$ & Shivering score $(1 / 2 / 3 / 4)$ \\
\hline
\end{tabular}




\section{Table3: Comparison of hemodynamic and temperature variations in groups at time}

sections $(\mu \pm \delta)$

\begin{tabular}{|c|c|c|c|c|c|c|}
\hline Pvalue & End of & Beginning of & End & After & Basal & Variables \\
\hline & Recovery & Recovery & Operation & Anesthesia & & \\
\hline & & & & & & Granisetron \\
\hline$<0.0001$ & $91.9 \pm 10.8$ & $92.2 \pm 12.7$ & $\ddagger 84.7 \pm 15.4$ & $88.9 \pm 18.9$ & $97.9 \pm 12.1$ & Mean Arterial pressure \\
\hline 0.002 & $76.5 \pm 10.2$ & $76.6 \pm 10.7$ & $\neq 69.5 \pm 14.5$ & $74.2 \pm 18.6$ & $81.7 \pm 11.7$ & Diastolic Blood Pressure \\
\hline 0.54 & $122.8 \pm 14.9$ & $123.3 \pm 19.7$ & $115.2 \pm 20.1$ & $118.5 \pm 21.4$ & $130.5 \pm 15.8$ & Systolic Blood Pressure \\
\hline 0.002 & $77.2 \pm 18.1$ & $83.3 \pm 15.1$ & $77.8 \pm 13.6$ & $82.9 \pm 12.2$ & $88.9 \pm 15$ & Heart Rate \\
\hline$<0.0001$ & $36.4 \pm 0.59$ & キ†35.8 \pm 0.57 & $\neq \dagger 35.7 \pm 0.66$ & $36.6 \pm 0.48$ & $37 \pm 0.58$ & Central temperature \\
\hline \multirow[t]{2}{*}{$<0.0001$} & $0.83 \pm 35.4 \neq \square$ & $0.73 \pm 35.1 \neq \square$ & $1.14 \pm 34.8$ 扣 & $0.59 \pm 35.9 \neq \square$ & $36.2 \pm 0.87$ & Peripheral temperature \\
\hline & & & & & & Ondansetron \\
\hline 0.075 & $92.6 \pm 11.9$ & $91.5 \pm 11.8$ & $95.2 \pm 11.9$ & $98.5 \pm 18.9$ & $91.5 \pm 10.2$ & Mean Arterial pressure \\
\hline 0.017 & $78.4 \pm 10.4$ & $77 \pm 9.7$ & $80.5 \pm 11.3$ & $84 \pm 16.8$ & $75.7 \pm 8.2$ & Diastolic Blood Pressure \\
\hline 0.3 & $120.8 \pm 16.3$ & $120.3 \pm 18$ & $124.6 \pm 16.3$ & $127.6 \pm 24.5$ & $123.2 \pm 17.3$ & Systolic Blood Pressure \\
\hline 0.009 & $74.1 \pm 13.1$ & $78.5 \pm 14.5$ & $78.5 \pm 10.3$ & $85.8 \pm 18.2$ & $81.4 \pm 13.6$ & Heart Rate \\
\hline$<0.0001$ & $36.5 \pm 0.57$ & $36.5 \pm 0.51$ & $36.3 \pm 0.67$ & $36.9 \pm 0.67$ & $37.1 \pm 0.59$ & Central temperature \\
\hline \multirow[t]{2}{*}{$<0.0001$} & $36.1 \pm 0.58$ & $35.7 \pm 0.67$ & $35.7 \pm 0.82$ & $36.6 \pm 0.41$ & $36.9 \pm 0.46$ & Peripheral temperature \\
\hline & & & & & & Pethidine \\
\hline$<0.0001$ & $90.7 \pm 7.3$ & $90.3 \pm 12.4$ & $98.5 \pm 13.9$ & $94.5 \pm 16.6$ & $100.6 \pm 14.9$ & Mean Arterial pressure \\
\hline 0.003 & $76 \pm 6.8$ & $75.7 \pm 11.1$ & $74.6 \pm 12.6$ & $79.8 \pm 15.6$ & $84.3 \pm 14.6$ & Diastolic Blood Pressure \\
\hline$<0.0001$ & $120.1 \pm 10.2$ & $119.5 \pm 16.5$ & $116.3 \pm 17.6$ & $123.8 \pm 20.1$ & $133.1 \pm 17.4$ & Systolic Blood Pressure \\
\hline$<0.0001$ & $71.3 \pm 8.3$ & $81 \pm 12$ & $79.9 \pm 12.6$ & $85.2 \pm 12.7$ & $87.3 \pm 14.2$ & Heart Rate \\
\hline$<0.0001$ & $36.6 \pm 0.59$ & $36.3 \pm 0.6$ & $36.2 \pm 0.63$ & $36.8 \pm 0.53$ & $37.3 \pm 0.58$ & Central temperature \\
\hline 0.54 & $35.5 \pm 0.91$ & $35.1 \pm 0.73$ & $34.9 \pm 0.77$ & $35.9 \pm 0.63$ & $36.2 \pm 0.87$ & Peripheral temperature \\
\hline
\end{tabular}

†Significant compared with the pethidine group. using repeated measure ANOVA and the Bonferroni test;

‡ Significant compared with the ondansetron group

૫ Significant comparison between ondansetron and pethidine groups 


\section{Figures}

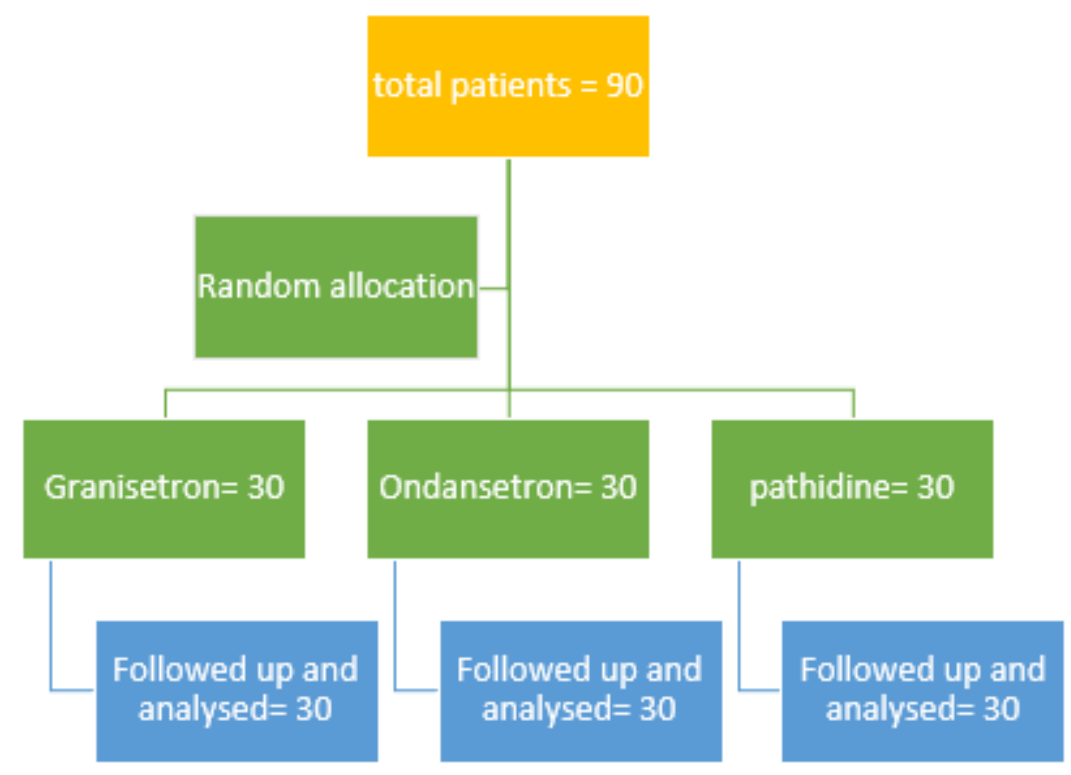

Figure 1

Randomly allocation and followed up flowchart

\section{Supplementary Files}

This is a list of supplementary files associated with this preprint. Click to download.

- Granisetron.sav

- CONSORT2010Checklist1.doc 